\title{
REVIEW
}

\section{Deliberate Self-harm and Suicide in Adolescents}

\author{
Donald E. Greydanus ${ }^{1,2}$ and Daniel Shek ${ }^{3}$ \\ ${ }^{1}$ Pediatrics \& Human Development, Michigan State University College of Human Medicine, Michigan, USA \\ ${ }^{2}$ Kalamazoo Center for Medical Studies, Michigan, USA \\ ${ }^{3}$ Department of Applied Social Sciences, The Hong Kong Polytechnic University, Hong Kong, China (PRC)
}

(Received for publication on February 3, 2009)

(Revised for publication on April 1, 2009)

(Accepted for publication on April 16, 2009)

\begin{abstract}
Deliberate self-harm (DSH) is a widespread yet often hidden problem in adolescents and young adults. Though most DSH can be classified as "non-suicidal self-cutting", some do go on to commit suicide. In this paper, deliberate self-harm is examined, including its prevalence, etiology, management, and future research directions using self-cutting and self-burning as examples. This article reviews recent literature to help understand what is known about self-cutting behavior and its potential relationship to suicide as well as provide direction for research. Research shows that different ecological factors at the individual, family, peer, and societal levels are related to deliberate self-harm. Although there is an association between some self-injurers and drug abuse (including alcohol abuse) as well as eating disorders, there are various subgroups of self-cutters and most are not at high risk for suicide. However, all acts of self-injury should be taken seriously by health care professionals and comprehensive therapy offered to any adolescent with a history of DSH. Future research directions on deliberate self-harm are also discussed. (Keio J Med 58 (3) : 144-151, September 2009)
\end{abstract}

Keywords: self-injury, suicide, adolescents

\section{Introduction}

The tragedy of suicide in adolescents is a global phenomenon that deserves the attention of the world's pediatricians. ${ }^{1-3}$ An estimated 2 million people die each year as a result of homicide or suicide. In 2002, there were an estimated 877,000 suicides in the world, of which approximately 200,000 were adolescents and young adults. $^{4-7}$ Even when controlling for global population growth, suicide is among the leading causes of death for adolescents in the world and rates are rising faster in teens than in other age groups. Of 4 million worldwide suicide attempts each year, at least 90,000 adolescents (up to age 19) successfully complete, with one successful suicide in every 5 minutes. Global suicide rates are now at a crisis level and will require nothing short of a call to action to effect change in these rates.

Suicide rates vary from country to country depending on local factors, including reporting methods (Table 1).
Among the major causes of death in youth around the world, suicide ranks fifth or higher in all countries under study (Table 2). Causes of suicide include depression, abuse (physical or sexual), loss of friends (including boy- or girlfriend), academic failure, social isolation, substance abuse, and others. Some youth who attempt or complete suicide have a history of self-cutting behavior. This article aims to examine the current research on the nature of deliberate self-harm with specific focus on selfcutting behavior and its potential link to suicide.

\section{Background}

Deliberate self-harm (DSH) is not an illness but a behavior defined "as an act by an individual with the intent of harming himself/herself physically." harm are summarized in Table $3^{9-14}$ with the most common methods being overdosing, self-poisoning and selfcutting in non-fatal injuries. ${ }^{15}$ In terms of background

Reprint requests to: Donald E. Greydanus, MD, FAAP, FSAM, FIAP (H), Pediatrics \& Human Development, Michigan State University College of Human Medicine; Kalamazoo Center for Medical Studies, 1000 Oakland Drive, Kalamazoo, Michigan 49008, USA, E-mail: Greydanus@kcms.msu.edu 
Table 11996 Global suicide rates (per 100,000) by gender and age group (i.e, 15 to 24 year olds*) of different countries

\begin{tabular}{l|c|c}
\hline \hline Country & Males & Females \\
\hline Greece & 3.8 & 0.8 \\
Portugal & 4.3 & 2.0 \\
Italy & 5.7 & 1.6 \\
Spain & 7.1 & 2.2 \\
Netherlands & 9.1 & 3.8 \\
Sweden & 10.0 & 6.7 \\
Japan & 10.1 & 4.4 \\
Israel & 11.7 & 2.5 \\
United Kingdom & 12.2 & 2.3 \\
Germany & 12.7 & 3.4 \\
Denmark & 13.4 & 2.3 \\
France & 14.0 & 4.3 \\
Bulgaria & 15.4 & 5.6 \\
Czech Republic & 16.4 & 4.3 \\
Poland & 16.6 & 2.5 \\
Ukraine & 17.2 & 5.3 \\
Hungary & 19.1 & 5.5 \\
Austria & 21.1 & 6.5 \\
Ireland & 21.5 & 2.0 \\
United States & 21.9 & 3.8 \\
Belarus & 24.2 & 5.2 \\
Canada & 24.7 & 6.0 \\
Switzerland & 25.0 & 4.8 \\
Australia & 27.3 & 5.6 \\
Norway & 28.2 & 5.2 \\
Estonia & 29.7 & 10.6 \\
Finland & 33.0 & 3.2 \\
Latvia & 35.0 & 9.3 \\
Slovenia & 37.0 & 8.4 \\
New Zealand & 39.9 & 6.2 \\
Russian Federation & 41.7 & 7.9 \\
Lithuania & 44.9 & 6.7 \\
\hline
\end{tabular}

*World Health Organization: http://www.unicef.org/pon96/insuicid.htm

factor, females usually outnumber males. ${ }^{16}$ In Western countries, $5-8 \%$ of adolescents report self-harm each year because of risk factors such as depression, drug abuse, anxiety disorders, and poverty. ${ }^{14}$ High risk factors for overt suicide in DSH include a strong suicidal intent, concomitant psychiatric disorders, using a method of high lethality (e.g., gun), and taking measures against being discovered. ${ }^{14}$ Thus, self-injurious behavior is an important issue which will be considered in great detail in this paper.

\section{Prevalence of Deliberate Self-harm}

Many studies around the world have verified the existence of DSH such as self-cutting behavior as an established phenomenon in youth (Table 4). For example, a study of $1,0369^{\text {th }}$ to $12^{\text {th }}$ graders in the Western part of the United States by Yates and colleagues identified rates of self-cutting that ranged from $26 \%$ to $37 \% ; 51.2 \%$ were females and major underling factors included criticism by and alienation from parents. ${ }^{17} \mathrm{Li}$ reviewed medical records in eastern Taiwan and identified $1 \%$ of
Table 2 Causes of death in adolescents/young adults in different countries (decreasing order of frequency) $1,2,5$

\begin{tabular}{|c|}
\hline Africa: AIDS, Other IFs*, Homicide/War, UIs**, Suicide \\
\hline SE ASIA: UIs, Other IFs, AIDS, Suicide, Homicide/War \\
\hline $\begin{array}{l}\text { South America/Caribbean: Homicide/War, UIs, Suicide, Other IFs, } \\
\text { AIDS }\end{array}$ \\
\hline $\begin{array}{l}\text { Western Pacific } \dagger \text { : UIs, Suicide, Other IFs, Homicide/War, AIDS } \\
\uparrow \text { Australia, New Zealand, China, Japan, Korea, Malaysia, } \\
\text { Micronesia, Philippines, Singapore, Vietnam, and others in } \\
\text { this area. }\end{array}$ \\
\hline Europe: UIs, Suicide, Homicide/War, Other IFs, AIDS \\
\hline $\begin{array}{l}\text { Eastern Mediterranean } \uparrow \text { : UIs, Other IFs, Homicide/War, AIDS, } \\
\text { Suicide } \\
\quad † \text { Afgahanistan, Egypt, Iraq, Jordan, Saudi Arabia, Israel, and } \\
\quad \text { other Middle East Countries. }\end{array}$ \\
\hline North America: UIs, Suicide, Homicide, Cancer, Other IFs, AIDS \\
\hline
\end{tabular}

all injuries were for deliberate self-harm; $80 \%$ of this DSH involved stabbing or cutting injuries and alcohol use was a major risk factor for the reported deliberate self-harm. ${ }^{18}$

Nixon and colleagues conducted a population-based study that examined the prevalence of self-cutting and related behaviors among community-based youth aged 14-21 year olds in Canada. ${ }^{19}$ They noted that $17 \%$ reported self-harming behavior with a mean age of onset of 15.2 years of age and $83 \%$ of self-destructive behavior involved cutting, scratching, or self-hitting. Help was sought in $56 \%$ of these individuals and self-harm was related to depression and attention-related problems. ${ }^{19}$

Morey et al. did a cross-sectional survey of 3,881 Irish teens (with $85 \%$ response rate) and noted that $9.1 \%$ had a lifetime history of deliberate self-harm in which females outnumbered males (13.9\% to $4.3 \%$ ) and self-cutting was more common than drug overdose $(66 \%$ to $35 \%) .{ }^{20}$ Another study in Great Britain by O'Loughlin and Sherwood identified 4,474 episodes of deliberate self-harm in one British town from 1981 to 2000; rates were highest in females who tended to use overdose as their method of self-harm versus males who were more likely to use self-cutting. ${ }^{21}$ The cohort with the highest rate of self-harming behavior was the 15 to 24 year age group and there was less repetitive DSH if the first episode was followed by psychiatric management. ${ }^{21}$

De Leo and Heller carried out a cross-sectional study on 3,757 adolescent students in Australia in which 6.2\% reported deliberate self-harm in the 12 months prior to the study with self-cutting found in 59\% and drug overdose in $30 \% .^{22}$ Underlying factors that were identified in these adolescent self-harmers included having ineffective coping skills such as self-blame and similar self-injurious behavior in family or friends. Most of these self- 
Table 3 Methods of self-harm ${ }^{9-14}$

\begin{tabular}{l}
\hline 1. Drug Overdose \\
2. Self-Poisoning \\
3. Self-Cutting \\
4. Other forms of self-mutilation \\
a. Self-hitting (battery) \\
b. Pinching \\
c. Scratching \\
d. Biting \\
e. Burning \\
5. Self-shooting \\
6. Hanging \\
7. Jumping from high places \\
8. Jumping into wells \\
\hline
\end{tabular}

harmers did not seek help before resorting to self-injurious behavior and thus, preventive programs for such behavior were recommended. ${ }^{22}$

Ystgaard et al. conducted a self-report survey of 4,060 $11^{\text {th }}$ graders in Norway who were 15 to 16 years of age. ${ }^{23}$ One or more acts of self-harm were reported in $6.6 \%$ of these youth in which self-cutting was seen in $74 \%$ of the DSH versus $17 \%$ for drug overdose. Only $6.1 \%$ of the self-cutters had contact with hospital personnel versus $47 \%$ of those having a drug overdose. General identified underlying factors included low self-esteem, drug abuse, similar behavior in friends, and major conflicts with parents; similar behavior in family members was particularly significant in males who committed acts of self-harm. ${ }^{23}$ Specific factors in females with DSH included a history of sexual abuse, anxiety, impulsivity, parental divorce, and alcohol abuse. ${ }^{23}$ Self-cutting and self-scratching behavior is increased in adult women diagnosed with drug-dependence disorders and also posttraumatic stress disorder (PTSD). ${ }^{24}$

In a clinical study by Hawton et al., 14,892 self-harm patients were identified in a United Kingdom general hospital gathered over a period of 23 years with 428 selfcutters versus 11,065 self-poisoners. ${ }^{25}$ The self-cutters were more often male, single, unemployed, had a history of deliberate self-harm, lived alone, and misused alcohol. ${ }^{25}$ One study of adolescents (11-18 years of age with a mean age of 15) who were self-cutters and were seen in intensive psychiatric programs revealed a range of self-cutting behavior. ${ }^{26}$ Those who are frequent self-cutters (i.e., over three times) were typically females who engage in high-risk behavior, such as sexual activity without consistent condom use and who had a history of sexual abuse. ${ }^{26}$ Matsumoto and colleagues showed that the prevalence for self-cutting and suicidal ideation in junior and senior high school students in Japan were $9.9 \%$ and $40 \%$ respectively. ${ }^{27}$

Setting fire to oneself is an unusual means of self-harm and suicide attempt that is seen more often in adults than in adolescents. ${ }^{28,29}$ Over an 11 year period (1994 to
Table 4 Prevalence of deliberate self-harm (DSH) behavior from various studies

\begin{tabular}{|c|c|c|}
\hline Author & Population & Prevalence \\
\hline 1. Yates ${ }^{17}$ & $\begin{array}{l}9^{\text {th }} \text { to } 12 \text { grade } \\
\text { (USA) }\end{array}$ & $26-37 \%$ (self-cutting) \\
\hline 2. $\mathrm{Li}^{18}$ & $\begin{array}{l}\text { Teens \& Adults } \\
\text { (Taiwan) }\end{array}$ & $\begin{array}{l}1 \% \text { of all injuries; } 80 \% \\
\text { self-cutting }\end{array}$ \\
\hline 3. Nixon ${ }^{19}$ & $\begin{array}{l}\text { 14-21 year olds } \\
\text { (Canada) }\end{array}$ & $\begin{array}{l}17 \% \text { DSH; } 83 \% \text { : cutting, } \\
\text { scratch, self-hitting }\end{array}$ \\
\hline 4. Morey 20 & $\begin{array}{l}\text { 3,881 Irish } \\
\text { Teenagers }\end{array}$ & $\begin{array}{l}9.1 \% \text { DSH; } 66 \% \text { : } \\
\text { self-cutting }\end{array}$ \\
\hline 5. De Leo ${ }^{22}$ & $\begin{array}{l}\text { 3,754 Teens } \\
\text { (Australia) }\end{array}$ & $\begin{array}{l}6.2 \% \text { DSH past } 12 \text { months } \\
\text { of survey }\end{array}$ \\
\hline 6. Ystgaard ${ }^{23}$ & $\begin{array}{r}4.060 \text { Teens } \\
\text { (Norway) }\end{array}$ & $\begin{array}{l}\text { 6.6\% DSH; } 74 \%: \\
\text { self-cutting }\end{array}$ \\
\hline 7. Matsumoto ${ }^{27}$ & $\begin{array}{c}\text { Teenagers } \\
\text { (Japan) }\end{array}$ & $\begin{array}{l}9.8 \% \text { DSH with } \\
\text { self-cutting }\end{array}$ \\
\hline
\end{tabular}

2005), 1,745 patients were admitted to a tertiary care burn unit in the United Kingdom; this included 41 patients with a mean age of $29 \pm 12$ years who had a burn following an assault and 86 patients (mean age of $37 \pm$ 12) who had self-induced burns. ${ }^{30}$ Gasoline, accelerants, and other flammable liquids were the means used for the burns and the rate of mortality was $29 \%$ in the self-burn patients.

In summary, deliberate self-harm is a widespread yet often hidden problem in adolescents, especially females, which shows both similarities and differences internationally. ${ }^{31}$

\section{Etiology of Deliberate Self-harm}

Ecological models have been commonly used to understand suicide and related behavior, where an individual's behavior is seen as a result of the interaction of different ecological systems (Table 5). For example, Shagle and Barber used a social-ecological framework to analyze adolescent suicidal ideation where family, school, peers and religion were proposed to influence adolescent suicidal ideation via self-derogation. ${ }^{32}$ Jackson and Nuttall ${ }^{33}$ and Perkins and Hartless ${ }^{34}$ similarly supported the use of an ecological risk-factor model for examining suicidal behavior in children and adolescents.

With reference to the personal system, research findings show that hopelessness was related to suicide and related behavior. ${ }^{35,36}$ Previous research also showed that adolescents with affect dysregulation, ${ }^{37}$ problem solving deficits, ${ }^{38}$ and low self-esteem ${ }^{39}$ had increased chance of suicide. With specific reference to the role of emotions in deliberate self-harm, adolescents engage in non-suicidal self-injury to influence behaviors of others and to deal with internal emotions. ${ }^{40}$ Two pathways to selfwounding have been identified: cutting may result when 
Table 5 Etiology of deliberate self-harm

\begin{tabular}{l}
\hline 1. Suicidal ideation \\
2. Feelings of hopelessness \\
3. Low self-esteem \\
4. Depression \\
5. Impulsivity \\
6. Family dysfunction and conflict \\
7. Bullying and intimidation in school \\
8. Poverty \\
9. Others (See text) \\
\hline
\end{tabular}

there is a steady increase of tension until a threshold is reached (the "spring" path), or as a result of the "switching on" of the impulse (the "switch-path"). Dissociation during cutting and a craving for cutting were more often associated with switching to this impulse. ${ }^{17,41}$ Furthermore, two main personal characteristics in adolescent self-harmers are having overwhelmingly negative emotion and self-derogation. Reasons noted for the non-suicidal self-injury include efforts to resist thoughts of suicide, expression of self-anger or disgust, resolve times of dissociation, influence others, or seek help from others. ${ }^{42,43}$

Research findings also showed that deliberate selfharm was related to individual psychological well-being. A study of 201 adolescents in a juvenile detention center in Japan noted that $16.4 \%$ had cut themselves at least once and $35 \%$ had burned themselves at least once. ${ }^{44}$ Those who had both self-cutting and self-burning behaviors had increased rates of depression and dissociation while those who had self-burning without cutting had less psychopathology. Studies also demonstrated that factors underlying deliberate self-harm included different forms of psychopathologies, ${ }^{45}$ such as schizophrenia, major depression, and substance abuse disorders; ${ }^{28,46,47}$ there is an association of drug abuse (including alcohol abuse) and eating disorders with some self-injurers. ${ }^{48}$ Deliberate self-harm is also associated with personality disorders. ${ }^{49,50}$ However, self-cutting can also arise de novo without any overt history of trauma or borderline personality disorder. ${ }^{51}$

Nevertheless, the type of self-harm does not necessarily identify the seriousness of the underlying psychopathology. Cryole, for example, studied 280 college undergraduates and noted that $31 \%$ had "minor" self-harming behavior characterized by skin picking or fingernail biting over the previous three years; $20 \%$ had "major" selfinjurious behavior with self-cutting and self-burning. ${ }^{52}$ Both groups were associated with underlying psychopathology, including disordered eating patterns (with negative self-esteem) ${ }^{53}$ negative thinking, ${ }^{53}$ impulsivity, somatic issues, and obsessive-compulsive issues. ${ }^{31}$

From the family perspective, different family processes are postulated to be related to adolescent suicidal behavior. Richman ${ }^{54}$ proposed that communication disturbanc- es and excessive secretiveness were family factors that might lead to heightened suicidal behavior. Research findings demonstrated that parent-adolescent communication was associated with adolescent suicidal ideation and adolescent deliberate self-harm. ${ }^{55,56}$ Syed and Khan showed that family conflict was the main factor contributing to deliberate self-harm in young people in Pakistan. ${ }^{57}$ Besides, a major factor often found in many selfcutting youth is severe family dysfunction that induces variable states of depersonalization and an altered state of mind or dissociation. ${ }^{58,59}$ Finally, self-cutting may be noted in youth who suffer from sexual or physical abuse, ${ }^{49,60,61}$ severe family neglect, ${ }^{62}$ early separation from parents, being homeless, and running from home. ${ }^{63}$ Other research notes the importance of parental alienation (with intense parental criticism) in adolescents with non-suicidal self-injury (NSSI such as self-cutting, selfhitting, self-burning). ${ }^{17}$

Studies have indicated that peer factors are related to adolescent suicide and related behavior. Research studies showed that number of friends and relationship problems with peers (e.g. conflict, bully-victim problem, intimidation) were significantly related to the degree of suicidal ideation. ${ }^{64}$ Intense conflicts with peers can induce DSH especially being a victim of bullying. ${ }^{65}$ Such internal conflicts can result in attention-seeking behavior and impulsivity that leads to DSH. ${ }^{11}$ Self-cutting may occur in attempts to relieve "a terrible state of mind" in those engaged in such behavior. ${ }^{31}$ The self-cutting behavior, though confusing to others, often serves as a way of releasing intense and unbearable pain from suppressed negative feelings driven by underlying depression and anxiety from conflicts with family and/or peers. ${ }^{12,19,66-68}$ On the other hand, social support was found to be an important protective factor against suicidal ideation. ${ }^{69}$

There are studies showing that macro socio-cultural factors are related to deliberate self-harm in adolescents. Social integration and social regulation were found to be negatively related to suicide in the United States from 1930 to $2000 .{ }^{70}$ Hawton et al. found that socioeconomic deprivation was related to deliberate self-harm. ${ }^{71}$ In an attempt to examine the relationship between area characteristics, individual characteristics and self-harm repetition, Johnston and colleagues showed that four individual factors (i.e., previous self-harm attempts, history of psychiatric treatment, employment status, and marital status) and proportion of Caucasian people in an area were related to deliberate self-harm. ${ }^{72}$ Added to this, Wenz also reported that low economic status was related to self-injury rates. ${ }^{73}$ Self-burning may occur as a result of war-induced post-traumatic stress disorder and may also be encouraged by media accounts of such incidents. ${ }^{74}$ 


\section{DSH and Risk for Suicide}

Though youth with evidence of deliberate self-harm such as self-cutting vary widely in the underlying causes, all youth with evidence of DSH must be taken seriously and carefully evaluated for risk of eventual or completed suicide. ${ }^{75}$ If underlying factors are not corrected (such as psychiatric problems as well as chronic conflicts with peers or parents), these acts of DSH can become repetitive, involve severe self-mutilation and multiple methods of $\mathrm{DSH},{ }^{65,75}$ increased depression with suicidal ideation, and also suicide attempts stemming from very negative attitudes towards life. ${ }^{68}$ Suicide is usually the result of chronic problems in those who are self-cutters; however, acute reactions can also lead to suicide in infrequent situations. ${ }^{68}$

The overall risk of suicide increases after a self-harm episode over time, with a $1.7 \%$ increase after 5 years, $2.4 \%$ at 10 years, and $3.0 \%$ at 15 years. ${ }^{76}$ Approximately $5 \%$ of self-harm patients seen at an emergency department or hospital commit suicide within 9 years of the self-harm incident. ${ }^{14}$ Males with bulimia and males who experience analgesia during self-cutting are especially at risk for suicide. ${ }^{59,77}$ Youth who cut their wrists have higher suicide risks than arm-cutters, though the latter is associated with more dissociation. ${ }^{78}$ Children who suffer from sexual abuse later developed increased risks for selfcutting behavior with increased association with eating disorders and suicidal ideation. ${ }^{60}$ In a study of 11,583 patients with deliberate self-harm in Oxford, England from 1978 to $1997,39 \%$ had repeated DSH and the highest risk for suicide was found in females with multiple DSH episodes. ${ }^{79}$

\section{Management}

It is important not to assume that the youth's self-cutting behavior is "harmless" and only reflects "harmless" attention-seeking behavior. ${ }^{11}$ Self-cutters are not a homogenous group and all should be considered at high risk of suicide that requires careful evaluation and management in this regard. ${ }^{80}$ For example, adults may be wrongfully accused of inducing burns in children unless a careful forensic examination takes place to identify self-induced burns versus assault with burns. ${ }^{81}$ The Internet may encourage self-harming behavior by normalizing and encouraging such behavior among adolescents. ${ }^{82}$ Thus, it is important for clinicians to ask about DSH and correct any misconception of normalcy with regard to any DSH behavior. An evaluation by the clinician may reveal skin trauma consistent with previously undiagnosed self-cutting. ${ }^{83}$ Youth who engage in selfcutting behaviors have increased risk for various highrisk behaviors and should be asked about sexual activity, condom use if sexually active, history of sexually transmitted diseases, and illicit drug use. ${ }^{84}$
Unfortunately, most self-cutters do not come to the attention of healthcare providers. ${ }^{20}$ In a study of young adults with DSH, only half sought help from professionals and those who did rated the care they received in a hospital emergency department as poor. ${ }^{85}$ The risk for suicide increases with time after this behavior, as noted before, and it is best to provide thorough protection and intensive monitoring rather than ignore the $\mathrm{DSH}$, potentially ending up with a later suicide. ${ }^{11}$ Multiple intervention modalities can be used to manage DSH, including group therapy, school-based interventions, hospitalization, art therapy, and anti-depressant medication for depression. ${ }^{17}$ Therapy needs to build skills for improved communication skills, management of stress, and development of positive coping mechanisms. ${ }^{40}$ Those engaged in repetitive self-wounding need intensive therapy. ${ }^{40}$ Monitoring deliberate self-harm presentations to general hospitals is also important. ${ }^{86}$

In a meta-analysis of suicide data from 18 studies, there was no evidence that intervention after self-harm actually reduced later suicide. ${ }^{87}$ Thus, more research on successful intervention strategies is clearly needed. Factors leading to successful intervention include having a trusting relationship with a health care professional, the availability of support during times of crisis, intensive management of concurrent psychiatric illness, and continuing support of family and friends. ${ }^{14}$

Preventive programs should be developed that will allow methods of managing stress and problem-solving. ${ }^{68}$ Mitchell and Ybarra also suggested that chat room and instant messaging should be added to telephone hotlines to prevent deliberate self-harm. ${ }^{88}$ However, Fortune and colleagues pointed out that "little is known about young peoples' views on prevention of DSH." 89

\section{Existing Research Gaps and Future Research Directions}

Although much work has been done to examine the phenomenon of deliberate self-harm in young people, a survey of the literature shows that existing studies on deliberate self-harm, particularly on self-cutting, are not adequate. For example, a computer search of PsycINFO using the key word "self-cutting" in November 2008 showed that there were only 103 citations. Obviously, more research in this area should be conducted.

Regarding future research in this area, there are several major possible directions. In the first place, although the present review shows that ecological factors at the individual, interpersonal and family contexts are related to deliberate self-harm, there are at least two areas that should be further researched. First, systematic studies on the role of spirituality in deliberate self-harm are few. A computer search of PsycINFO using the key word "selfharm" and "spirituality" in October 2008 showed that there was no related citation. As deliberate self-harm is a 
precursor to actual suicidal attempts which might lead to termination of life, it is both theoretically and practically important to explore the possible role of spirituality such as life meaning in self-harmers. As spirituality is a growing concern in the mental health contexts, ${ }^{90,91}$ more work along this line should be carried out. Second, although the present review highlights the importance of family processes in deliberate self-harm, further work is needed to examine how specific family processes such as different types of parental control and parental marital qualities and related experiences are related to deliberate self-harm. ${ }^{92}$ As deliberate self-harm is commonly regarded as a signal to seek help, how family processes may inhibit the healthy help-seeking processes among adolescents should be explored.

Third, most of the existing studies investigating the antecedents and consequences of deliberate self-harm are cross-sectional studies. Although cross-sectional studies can help to identify the correlates of deliberate self-harm, causal relationships involved cannot be clearly established. Fourth, this literature review reveals that with a few exceptions, quantitative methods have been primarily used to study deliberate self-harm. While a post-positivistic approach represents the dominant research paradigm in medical and social science research, its limitations should be duly acknowledged. Methodologically, it would be illuminating if qualitative research adopting constructionist orientations could be carried out in future. Fifth, comparative studies should be conducted to examine deliberate self-harm in different communities. As commented by Madge et. al., "there is little reliable comparative international information on its extent or characteristics" (p.667) ${ }^{93}$ In view of the rising suicide figures in different non-Western communities such as Hong Kong, ${ }^{94}$ comparisons regarding deliberate selfharm among different communities would be important.

Finally, research on intervention programs for deliberate self-harm should be carried out. For tertiary prevention, relative efficacy of different intervention approaches should be examined. For secondary prevention, identification of adolescents with self-harming behavior that deserves professional attention at an earlier stage is important. This requires the development of screening instruments with good psychometric properties. Similarly, primary prevention programs that reduce young people's likelihood of engaging in deliberate self-harm is of paramount importance. Based on the perspective of positive youth development, it is argued that strengthening young people's psychosocial competence and developmental assets in young people would reduce their likelihood to engage in deliberate self-harm behavior. ${ }^{95,96}$

\section{Summary}

Deliberate self-harm is a widespread yet often hidden problem in adolescents, especially females, which shows both similarities and differences internationally. ${ }^{31}$ Two main characteristics of DSH noted are negative emotion and self-derogation. Reasons for non-suicidal self-injury include efforts to resist suicidal thoughts, expression of self-anger or disgust, resolve times of dissociation, influence others, or seek help from others. ${ }^{42,43}$ There is an association of drug abuse (including alcohol abuse) and eating disorders with self-injurious behavior. ${ }^{48}$ There are various subgroups of self-cutters and most are not at high risk for suicide. ${ }^{97}$ However, all acts of self-injury should be taken seriously by healthcare professionals and comprehensive therapy offered to any adolescent with a history of self-injury or DSH. Programs for suicide prevention should be implemented for youth who are at risk for suicide, including those who self-injure themselves. ${ }^{2,3,22,98-100}$ More research on deliberate selfharm should be carried out with reference to the research gaps identified in this paper.

\section{References}

1. Greydanus DE, Patel DR, Pratt HD, editors: Essential Adolescent Medicine. New York: McGraw-Hill; 2006

2. Greydanus DE, Calles Jr. JL: Suicide in children and adolescents. Prim Care: Clinics in Office Practice 2007; 34: 259-274

3. Greydanus DE, Ryan SA, Calles Jr. JL: Adolescent Suicide. American Academy of Pediatrics PREP Audio 2007; 2

4. Mann JJ, Apter A, Bertolote J, Beautrais A, Currier D, Haas A, et al: Suicide prevention strategies: a systematic review. JAMA 2005; 294: 2064-2074

5. Barker G: What about boys: a literature review in the health and development of adolescent boys. WHO Department of Child and Adolescent Health and Development. Geneva: Switzerland; 2000

6. Brown P: Choosing to die- a growing epidemic among the young. B World Health Organ 2001; 79: 1175-1177

7. Diekstra R: Suicide and the attempted suicide: an international perspective. Acta Psychiat Scand 1989; 80: 1-24

8. Issacson G, Rich CL: Management of patients who deliberately harm themselves. BMJ 2001; 322: 213-215

9. Clarke T, Baker P, Watts CJ, Henderson H, Evans T, Sherr L: Selfharm in younger people: audit of prevalence and provision. Psychol Health Med 2001; 6: 349-359

10. Lowenstein LF: Youths who intentionally practice self-harm. In: Merrick J, Zalsman G, editors. Suicidal Behavior in Adolescence. London: Freund Publishing House LTD; 2005; 95-104

11. Lowenstein LF: Youths who intentionally practice self-harm: review of recent research 2001-2004. Int J Adolesc Med Health 2005; 17: 225-230

12. Yip KS, Ngan MY, Lam I: An exploration of peer influence and response to adolescent self-cutting behavior in Hong Kong. Smith College Studies Soc Work 2002; 72: 379-401

13. Yip KS, Ngan MY, Lam I: Pattern adolescent self-cutting in Hong Kong: reports from school social workers. Int J Adolesc Youth 2003; 11: $135-155$

14. Skegg K: Self-harm. Lancet 2005; 366: 1471-1483

15. Vajani M, Annest JL, Crosby AE, Alexander JD, Millet LM: Nonfatal and fatal self-harm injuries among children aged 10-14 years - United States and Oregon, 2001-2003. Suicide Life Threat 2007; 37: 493-506

16. Lundh LG, Karim J, Quilisch E: Deliberate self-harm in 15 year old adolescents: a pilot study with modified version of the Deliberate Self-Harm Inventory. Scand J Psychol 2007; 48: 33-41 
17. Yates TM, Tracy AJ, Luthar SS: Nonsuicidal self-injury among "privileged" youths: longitudinal and cross-sectional approaches to developmental process. J Consult Clin Psychol 2008; 76: 52 62

18. Li YM: Deliberate self-harm and relationship to alcohol use at an emergency department in eastern Taiwan. Kaohsiung J Med Sci 2007; 23: 247-253

19. Nixon MK, Cloutier P, Jansson SM: Nonsuicidal self-harm in youth: a population- based survey. CMAJ 2008; 178: 306-312

20. Morey C, Corcoran P, Arensman E, Perry IJ: The prevalence of self-reported deliberate self-harm in Irish adolescents. BMC Public Health 2008; 8: 79

21. O'Loughlin S, Sherwood J: A 20-year review of trends of deliberate self-harm in a British town, 1981-2000. Soc Psych Psych Epid 2005; 40: 446-453

22. De Leo D, Heller TS: Who are the kids who self-harm? An Australian self-report school survey. Med J Australia 2004; 181: 140-144

23. Ystgaard M, Reinholdt NP, Husby J, Mehlum L: Deliberate selfharm in adolescents. Tidsskr Nor Laegeforen 2003; 123: 2241 2245

24. Harned MS, Najavits LM, Weiss RD: Self-harm and suicidal behavior in women with comorbid PTSD and substance dependence. Am J Addict 2006; 15: 392-395

25. Hawton K, Harriss L, Simkin S, Bale E, Bond A: Self-cutters: patient characteristics compared with self-poisoners. Suicide Life Threaten 2004; 34: 199-208

26. Brown LK, Houck CD, Grossman CI, Lescano CM, Frenkel JL: Frequency of adolescent self-cutting as a predictor of HIV risk. J Dev Behav Pediatr 2008; 29: 161-165

27. Matsumoto T, Imamura F, Chiba Y, Katsumata Y, Kitani M, Takeshima T: Prevalences of lifetime histories of self-cutting and suicidal ideation in Japanese adolescents: differences by age. Psychiat Clin Neuros 2008; 62: 362-364

28. Thombs BD, Bresnick MG, Magyar-Russell G: Who attempts suicide by burning? an analysis of age patterns of mortality by selfinflicted burning in the United States. Gen Hosp Psychiat 2007; 29: $244-250$

29. Rashid A, Gowar JP: A review of the trends of self-inflicted burns. Burns 2004; 30: 573-576

30. Malic CC, Karoo RO, Austin O, Phipps A: Burns inflicted by self or by others- an 11 year snapshot. Burns 2007; 33: 92-97

31. Madge N, Hewitt A, Hawton K: Deliberate self-harm within an international community sample of young people: comparative findings from the Child and Adolescent Self-harm in Europe (CASE) Study. J Child Psychol Psyc 2008; 49: 667-677

32. Shagle SC, Barber BK: A social-ecological analysis of adolescent suicidal ideation. Am J Orthopsychiat 1995; 65: 114-124

33. Jackson H, Nuttall RL: Risk for preadolescent suicidal behavior: An ecological model. Child Adol Social Work J 2001; 18: 189_ 203

34. Perkins DF, Hartless G: An ecological risk-factor examination of suicide ideation and behavior of adolescents. J Adolescent Res 2002; 17: 3-26

35. Rutter PA, Behrendt AE: Adolescent suicide risk: four psychosocial factors. Adolescence 2004; 39: 295-302

36. Warman DM, Forman EM, Henriques GR, Brown GK, Beck AT: Suicidality and psychosis: Beyond depression and hopelessness. Suicide Life Threaten 2004; 34: 77-86

37. Khan AU: Heterogeneity of suicidal adolescents. J Am Acad Child Adoles Psych 1987; 26: 92-96

38. Asarnow JR, Carlson GA, Guthrie D: Coping strategies, self-perceptions, hopelessness, and perceived family environments in depressed and suicidal children. J Consult Clin Psych 1987; 55: 361 $-366$

39. Kelly TM, Lynch KG, Donovan JE, Clar DB: Alcohol use disorders and risk factor interactions for adolescent suicidal ideation and attempts. Suicide Life Threaten 2001; 31: 33-40

40. Lloyd-Richardson EE, Perrine N, Dierker L, Kelley ML: Characteristics and functions of non-suicidal self-injury in a community sample of adolescents. Psychol Med 2007; 37: 1183-1192

41. Huband N, Tantam D: Repeated self-wounding: women's recollection of pathways to cutting and of the value of different interventions. Psychol Psychother 2004; 77: 413-428

42. Klonsky ED, Muehlenkamp JJ: Self-injury: a research review for the practitioner. J Clin Psychol 2007; 63: 1045-1056

43. Walsh B: Clinical assessment of self-injury: a practical guide. J Clin Psychol 2007; 63: 1057-1068

44. Matsumoto T, Yamaguchi A, Chiba Y, Takeshi A, Eizo I, Yoshio $\mathrm{H}$ : Self-burning versus self-cutting: patterns and implications of self-mutilation; a preliminary study of differences between selfcutting and self-burning in a Japanese juvenile detention center. Psychiatry Clin Neurosci 2005; 59: $62-69$

45. Fergusson DM, Michael T, Lynskey MT: Suicide attempts and suicidal ideation in a birth cohort of 16-year-old new Zealanders. J Am Acad Child Adolesc Psych 1995; 34: 1308-1317

46. Tsati E, Iconomou T, Tzivaridou D, Keramidas E, Papadopoulos S, Tsoutsos D: Self-inflicted burns in Athens, Greece: a six-year retrospective study. J Burn Care Rehabil 2005; 26: 75-78

47. James WA, Frierson RL, Balajepalli B, Lippmann SB: Suicide attempts by burning. J Ky Med Assoc 2006; 104: 459-467

48. Favaro A, Ferrara S, Santonastaso P: Self-injurious behavior in a community sample of young women: relationship with childhood abuse and other types of self- damaging behaviors. J Clin Psychiat 2007; 68: $122-131$

49. Favaro A, Santonastaso P, Monteleone P: Self-injurious behavior and attempted suicide in purging bulimia nervosa: associations with psychiatric comorbidity. J Affect Disord 2008; 105: 285-289

50. Paris J: Half in love with easeful death: the meaning of chronic suicidality in borderline personality disorder. Harvard Rev Psychiat $2004 ; 12$ : $42-48$

51. Marchetto MJ: Repetitive skin-cutting: parental bonding, personality, and gender. Psychol Psychother 2006; 79: 445-459

52. Croyle KL, Waltz J: Subclinical self-harm: range of behaviors, extent, and associated characteristics. Am J Orthopsychiat 2007; 77: $332-342$

53. Bjärehed J, Lundh LG: Deliberate self-harm in 14-year-old adolescents: how frequent is it, and how is it associated with psychopathology, relationship variables, and styles of emotional regulation? Cogn Behav Ther 2008; 37: 26-37

54. Richman J: Family therapy for suicidal people. New York: Springer; 1986

55. Portzky G, de Wilde EJ, van Heeringen K: Deliberate self-harm in young people: differences in prevalence and risk factors between the Netherlands and Belgium. Eur Child Adoles Psy 2008; 17: 179 $-186$

56. Stivers C: Parent-adolescent communication and its relationship to adolescent depression and suicide proneness. Adolescence 1988; 23: 291-295

57. Syed EU, Khan MM: Pattern of deliberate self-harm in young people in Karachi, Pakistan. Crisis: The Journal of Crisis Intervention and Suicide Prevention 2008; 29: 159-163

58. Wolfradt U, Veith C, Jany C, Frank D: Depersonalization and selfmutilation: An empirical study. Zeitschrift Klin Psychol Psychiatrie Psychotherapie 2002; 50: 75-90

59. Matsumoto T, Yamaguchi A, Asami T, Okada T, Yoshikawa K, Hirayasu Y: Characteristics of self-cutters among male inmates: association with bulimia and dissociation. Psychiatry Clin Neurosci 2005; 59: 319-326

60. Murray CD, MacDonald S, Fox J: Body satisfaction, eating disorders and suicide ideation in an Internet sample of self-harmers reporting and not reporting childhood sexual abuse. Psychol Health 2008; 13: 29-42

61. Yates TM, Carlson EA, Egeland B: A prospective study of child 
maltreatment and self-injurious behavior in a community sample. Dev Psychopathol 2008; 20: 651-671

62. Zoroglu SS, Tuzun U, Sar V et al: Suicide attempts and self-mutilation among Turkish high school students in relation with abuse, neglect, and dissociation. Psychiatry Clin Neurosci 2003; 57: 119 $-126$

63. Tyler KA,Whitbeck LB, Hoyt DR, Johnson KD: Self-mutilation and homeless youth: The role of family abuse, street experiences, and mental disorders. J Res Adolesc 2003; 13: 457-474

64. Sun RCF, Hui E, Watkins D: Towards a model of suicidal ideation for Hong Kong Chinese adolescents. J Adolescence 2006; 29: 209 $-224$

65. Bolognini M, Plancherel B, Laget J, Stephan P, Halfon O: Adolescents' self-mutilation: relationship with dependent behavior. Schweizerische Zeitschrift Psychologie 2003; 62: 242-249

66. Ross S, Heath N: A study of the frequency of self-mutilation in a community sample of adolescents. J Youth Adolesc 2002; 31: $67-$ 77

67. Kumar G, Pepe D, Steer RA: Adolescent psychiatric inpatients' self-reported reasons for cutting themselves. J Nerv Ment Dis 2004; 192: 830-836

68. Rodham K, Hawton K, Evans E: Reasons for deliberate self-harm: comparison of self-poisoners and self-cutters in a community sample of adolescents. J Am Acad Child Adolesc Psych 2004; 43: $80-87$

69. Kaslow NJ, Sherry A, Bethea K, Wyckoff S, Compton MT, Grall $\mathrm{MB}$, et al: Social risk and protective factors for suicide attempts in low income African American men and women. Suicide Life Threaten 2005; 35: 400-412

70. O'Brien RM: A common explanation for the changing age distributions of suicide and homicide in the United States, 1930 to 2000. Soc Forces 2006; 84: 1539-1557

71. Hawton K, Harriss L, Hodder K, Simkin S, Gunnell D: The influence of the economic and social environment on deliberate selfharm and suicide: an ecological and person-based study. Psychol Med 2001; 31: 827-836

72. Johnston A, Cooper J, Webb R, Kapur N: Individual- and arealevel predictors of self-harm repetition. Brit J Psychiat 2006; 189: 416-421

73. Wenz FV: Ecological variation in self-injury behavior. Suicide Life Threaten 1977; 7: 92-99

74. Bracs M, Loncar Z, Boban M, Gregurek R, Brajkovic L, Tomicic $\mathrm{H}$, et al: Self-inflicted burns in patients with chronic combat-related post-traumatic stress disorder. Coll Antropol 2007; 31: 1173 1177

75. Fortune S, Stewart A, Yadav V, Hawton K: Suicide in adolescents: using life charts to understand the suicidal process. J Affect Disord 2007; 100: 199-210

76. Hawton K, Zahl D, Weatherall R: Suicide following deliberate self-harm: long-term follow-up of patients who presented to a general hospital. Brit J Psychiat 2003; 182: 537-542

77. Matsumoto T, Imamura F, Chibi Y, Katsumata Y, Kitani M, Takeshima T: Analgesia during self-cutting: clinical implications and the association with suicidal ideation. Psychiat Clin Neuros 2008; 62: $355-358$

78. Matsumoto T, Yamaguchi A. Chiba Y, Asami T, Iseki E, Hirayasu Y: Patterns of self-cutting: a preliminary study on differences in clinical implications between wrist- and arm-cutting using a Japanese juvenile detention center sample. Psychiat Clin Neuros 2004; 58: $377-382$

79. Zahl DL, Hawton K: Repetition of self-harm and subsequent suicide risk: long-term follow-up study of 11,583 patients. Brit $\mathrm{J}$ Psychia 2004; 185: 70-75

80. Fortune SA: An examination of cutting and other methods of DSH among children and adolescents presenting to an outpatient psychiatric clinic in New Zealand. Clin Child Psychol Psychiatry 2006; 11: 407-416

81. Greenbaum AR, Donne J, Wilson D, Dunn KW: Intentional burn injury: an evidence-based, clinical and forensic review. Burns 2004; 30: 628-642

82. Whitlock JL, Powers JL, Eckenrode J: The virtual cutting edge: the internet and adolescent self-injury. Dev Psychol 2006; 42: 407 $-417$

83. Ahluwalia J, Lowenstein EJ: Case study: delicate skin cutting: management beyond the skin and implications of superficial habitual self-mutilation. SKINmed 2005; 4: 190-192

84. Brown LK, Houck CD, Hadley WS, Lescano CM: Self-cutting and sexual risk among adolescents in intensive psychiatric treatment. Psychiatr Serv 2005; 56: 216-218

85. Nada-Raja S, Morrison D, Skegg K: A population-based study of help-seeking for self-harm in young adults. Aust NZ J Psychiat 2003; 37: 600-605

86. Hawton K, Bale L, Casey D, Shepherd A, Simkin S, Harriss L: Monitoring deliberate self-harm presentations to general hospitals. Crisis 2006; 27: 157-163

87. Crawford MJ, Thomas O, Khan N, Kulinskaya E: Psychosocial interventions following self-harm: systematic review of their efficacy in preventing suicide. Brit J Psychiat 2007; 190: 11-17

88. Mitchell KJ, Ybarra ML: Online behavior of youth who engage in self-harm provides clues for preventive intervention. Prev Med 2007; 45: 392-396

89. Fortune S, Sinclair J, Hawton K: Adolescents' views on preventing self-harm: A large community study. Soc Psych Psych Epid 2008; 43: 96-104

90. Koenig HG: Religion, spirituality and aging. Aging Ment Health 2006; 10: $1-3$

91. Thompson I: Mental health and spiritual care. Nursing Standard 2002; 17: 33-38

92. Shek DTL: A longitudinal study of perceived parental psychological control and psychological well-being in Chinese adolescents in Hong Kong. J Clin Psychol 2007; 63: 1-22

93. Madge N, Hewitt A, Hawton K, de Wilde EJ, Corcoran P, Fekete $\mathrm{S}$, et al: Comparative findings from the Child \& Adolescent Selfharm in Europe (CASE) study. J Child Psychol Psyc 2008; 49: 667-677

94. Shek DTL, Lee BM, Chow JTW: Trends in adolescent suicide in Hong Kong for the period of 1980 to 2003. ScientificWorldJOURNAL 2005; 5: 702-723

95. Shek DTL: Conceptual framework underlying the development of a positive youth development program in Hong Kong. Int J Adolescent Medicine Health 2006; 18: 303-314

96. Shek DTL, Ma HK, Merrick J, editors: Positive youth development: development of a pioneering program in a Chinese context. London: Freund Publishing Company; 2002

97. Klonsky ED, Olino TM: Identifying clinically distinct subgroups of self-injurers among young adults: a latent class analysis. J Consult Clin Psychol 2008; 76: $22-27$

98. Centers for Disease Control and Prevention. Programs for the prevention of suicide among adolescents and young adults; and Suicide contagion and the reporting of suicide: recommendations from a national workshop. MMWR 1994; 43: 3-18

99. Frankenfield DL, Keyl PM, Gielen A, Wissow LS, Werthamer L, Baker SP, et al: Adolescent patients: healthy or hurting? Missed opportunities to screen for suicide risk in the primary care setting. Arch Pediatr Adolesc Med 2000; 154: 162-168

100. Omar HA: A model program for youth suicide prevention. Int $J$ Adolesc Med Health 2005; 17: 275-278 